\title{
Profits Allocation in Service Cooperation of Agricultural Products Logistics
}

\author{
Dengbing Zhang \\ School of Economics, Yancheng Institute of Technology, Jiangsu Yancheng, China \\ zdb879@263.net
}

Keywords: agricultural products; logistics; cooperation; profits allocation

\begin{abstract}
The inefficiency of agricultural product logistics is an important issues hindering the development of agricultural economy, and imperfect cooperation mechanism is the key to lead to inefficient agricultural products logistics. Profit allocation is the core content of agricultural product logistics cooperation mechanism. Two methods of Cooperation allocation are proposed in this paper, one method is based on input, another method is based on output. The article abstracts three basic agents of the agricultural product logistics cooperation, they are peasants, logistics providers, and supermarkets. The article states that the interests demanding of virtual alliance participants are competitive. On the principle of maximizing the profits , price negotiations are inevitable, which lead the virtual union very easy to collapse. By discussion on related agents in cooperation, it analyses the necessity of allocation and the effective allocation models of cooperative surplus.
\end{abstract}

\section{Introduction}

The individual motives based on profits maximization can lead to extremely bad results or serious injustice. Having been widely accepted by modern economic, unions become an important means of social cooperation. Studies on cooperation of agricultural product logistics services from benefit-sharing are of great significance. From view of game cooperation, this article discusses the forming mechanism of alliance and its cooperation model.

\section{Cooperative games and Union}

Definition 1. A cooperative game is the game in which there is at least one constrained contract signed after sufficient consultation.

In cooperative games, individuals have the goal of achieving Pareto optimality, and then optimize individual earnings.

Definition 2. Collection of all participants is denoted as $I=\{i 1, i 2, i 3, \ldots, i n\}$.

Definition 3. To a n-agents game, collection of all participants is $I$, if the members in subset $I_{i} \subset I$ can reach a binding agreement $\mathbb{C}$, Then $I_{i}$ forms a union $\widehat{I}_{i}$, s.t. $\mathbb{C}$.

\section{Union payoff functions and rational allocation}

\subsection{Union Payoff}

Definition 4. For collection of participants $I, \overparen{I_{i}}$ is a union, $u\left(\overparen{I_{i}}\right)$ is the alliance payoff.

And, the Union income is not less than the sum of sub-union's income, namely:

$u(\overparen{S \cup T}) \geq u(\widehat{S})+u(\widehat{T}), S \subset I, T \subset I, S \cap T=\varnothing$

\subsection{Cooperative Surplus And Rational Allocation}

Definition 5. Cooperative surplus is the difference between union payoff and sum of independent income of each player.

According to this definition, any market transactions are "cooperative" behavior, the existence of Cooperative surplus is a prerequisite for any cooperation. 
Realization of collective rationality in cooperative games is based on individual rationality as basic conditions.

To a n-people game, $I$ is a n-agents union, and a reasonable allocation scheme is $D=\left(d_{1}, d_{2}, \ldots, d_{n}\right)$.

Where,

(1) $d_{i} \geq u_{i}$, income of a participant from a union cannot be less than that of non-cooperative participant.

(2) $U(I)=\sum_{i=1}^{n} d_{i}$, all union payoffs is used for allocation.

Cooperation is the process that the participants bargain for more allocation from Cooperative surplus.

Example 1. People A has a product, and the value is 200 for him. People B thinks that it is worth of at the minimum value of 300 . How much is the possible price?

Analysis: B can bid between $(200,300)$, there may produce a "reasonable" deal, and create a cooperative surplus of 100 . For example, b bids 230, the allocation is A:30,B:70 . However, there are many reasonable trading price. Which one is fair to both sides? One possible deal is: $b$ bids 250 . It seems somewhat fair, and the two sides get an equal profit. But, if the two sides don't know the other's bottom/top line, the problem will become more complex.

\subsection{Two Methods Of Cooperative Allocation}

(1) Input-based allocation Method

The partners' investment contribution is often an important basis for surplus allocation. The difficulty is that investment of each participant is difficult to measure with a uniform scale. Because cooperation is always a complement to every one, they supply different resources to the union.

Example 2. The two companies launched a cooperation. The big company invest 900, while investment of the small company is 100 . The profit of their cooperation is 1200 . . How to allocate this profit?

Analysis: If input value can be evaluated according to the "cost", the allocation of cooperation remaining can be split proportionally according to how much their input is. In this way, partners are more likely to accept this plan.

(2) Output-based allocation methods

The basic idea of this method is, the bigger one contributes to the Cooperative surplus, the more he will get.

Example 3. A and B can earn 120,100 in the market dependently. If they unite, they can get 250 . How to distribute their income?

Analysis: the contribution of participant A to the union is $250-100=150$,while its independent income is 120 . So, the profit expectation of $A$ is $(150+120) / 2=135$. Similarly, the profit expectation of $\mathrm{B}$ is 115 . Therefore, according the output contribution, allocation plan $(135,115)$ is a fair result.

\subsection{Shapley Value}

Shapley value is an output-based allocation method.

The Shapley value is a method for n-agent cooperation to allocate the cooperation surplus. This method makes a rational allocation based on each participant's marginal contribution to the Union, making collective and individual rationality in balance .

Definition 6. The Shapley value $\varphi_{i}[V]$ is earning expectation of agent $\mathrm{i}$ in $\mathrm{n}$-agents cooperation $(I, V)$.

$$
\begin{aligned}
\varphi_{i}[V] & =\sum_{S \subset I} p(S-i) \Delta_{i}(S) \\
& =\sum_{S \subset I} \frac{(|S|-1) !(n-|S|) !}{n !}[V(S)-V[S-i]]
\end{aligned}
$$

where,

$|S|$ is the number of agents in $\mathrm{S}$.

$S-i$ is the participants collection before $\mathrm{i}$ join in. 
$p(S-i)=\frac{(|S|-1) !(n-|S|) !}{n !}$ is the probability of the combination $S-i$.

$\Delta_{i}(S)=V(S)-V[S-i]$ is the marginal contribution of participants $\mathrm{i}$.

\section{Agricultural products logistics cooperation game}

In logistics of agricultural products ,there exist three types of participants: farmers, logistics providers, supermarkets. Here, we did not take into account the consumers. Because of the high cost of consumers cooperation, cooperation may not produce the surplus.

Table 1 RESOURCES OF PARTICIPANTS

\begin{tabular}{|l|l|l|l|}
\hline & Farmer & Logistics providers & Supermarket \\
\hline Resources & $\begin{array}{l}\text { Agricultural } \\
\text { products }\end{array}$ & Logistics tools & $\begin{array}{l}\text { Sales channels and } \\
\text { marketing information }\end{array}$ \\
\hline
\end{tabular}

Table 2 MAIN PROPERTIES OF PARTICIPANTS IN AGRICULTURAL PRODUCTS LOGISTICS

\begin{tabular}{|l|c|c|c|}
\hline & Farmer & Logistics providers & Supermarket \\
\hline Cost & $C 1$ & $C 2$ & $C 3$ \\
\hline Production & $\mathrm{q} 1$ & - & - \\
\hline Loss ratio & $\mathrm{rw} 1$ & $\mathrm{rw} 2$ & $\mathrm{rw} 3$ \\
\hline unsalable & $\mathrm{qu} 1$ & $\mathrm{qu} 2$ & $\mathrm{qu} 3$ \\
\hline Sales & $\mathrm{qs} 1$ & $\mathrm{qs} 2$ & $\mathrm{qs} 3$ \\
\hline Unit price & $\mathrm{p} 1$ & $\mathrm{p} 2$ & $\mathrm{p} 3$ \\
\hline Profit & $\mathrm{u} 1$ & $\mathrm{u} 2$ & $\mathrm{u} 3$ \\
\hline
\end{tabular}

In one production cycle, cost is agents' payoff under the given resources condition, and unit price refers to the sale price or freight rates of agricultural products based on the total.

In the above variables, some are internal control variables of agents, which are can be effectively controlled by agents themselves. The increased profits made by improving these variables will be exclusively got by each agent. For example, farmers apply advanced science and technology and management techniques to improve yields, reduce costs, and increase profits. Logistics providers can adopt cold chain technology to reduce the consumption and increase profits.

These internal variable represents the intrinsic properties and individual abilities of the agents, and not effected by "cooperation".

Here, we discussed mainly in the context of cooperation with constant individual ability. And, this paper focuses on how to produce cooperative surplus by the agents' cooperation, thereby increasing effectiveness. Cooperation can change some variables, as shown in the following table:

Table 3 IMPACT OF THE COOPERATION ON THE AGENTS' PROPERTIES

\begin{tabular}{|l|c|c|c|c|c|c|c|}
\hline & \multicolumn{2}{|c|}{ Farmer } & \multicolumn{2}{c|}{ Logistics providers } & \multicolumn{2}{c|}{ Supermarket } \\
\hline Collaboration variables & rw1 & qu1 & qs1 & rw2 & qs2 & rw3 & qs3 \\
\hline $\begin{array}{l}\text { Farmer-Logistics } \\
\text { cooperation }\end{array}$ & $\downarrow$ & & $\uparrow$ & $\downarrow$ & $\uparrow$ & & \\
\hline $\begin{array}{l}\text { Farmer-supermarket } \\
\text { cooperation }\end{array}$ & & $\downarrow$ & $\uparrow$ & & & $\downarrow$ & $\uparrow$ \\
\hline $\begin{array}{l}\text { Logistics-supermarket } \\
\text { cooperation }\end{array}$ & & & & $\downarrow$ & $\uparrow$ & $\downarrow$ & $\uparrow$ \\
\hline full cooperation & $\downarrow$ & $\downarrow$ & $\uparrow$ & $\downarrow$ & $\uparrow$ & $\downarrow$ & $\uparrow$ \\
\hline
\end{tabular}




\section{Allocation in agricultural products logistics cooperation}

\subsection{Payoff Of Virtual Union}

Definition 7. Virtual Alliance is cooperation with non-binding agreements, in which the partners directly profit from the market, there is no allocation for cooperation.

Table 4 Profits of Virtual AlLiance

\begin{tabular}{|l|c|c|c|}
\hline & Farmer & Logistics providers & Supermarket \\
\hline no cooperation & 100 & 120 & 150 \\
\hline Farmer-Logistics cooperation & 105 & 130 & 150 \\
\hline $\begin{array}{l}\text { Farmer-supermarket } \\
\text { cooperation }\end{array}$ & 110 & 120 & 165 \\
\hline $\begin{array}{l}\text { oogistics-supermarket } \\
\text { cooperation }\end{array}$ & 100 & 126 & 160 \\
\hline full cooperation & 115 & 135 & 180 \\
\hline
\end{tabular}

But a virtual "Alliance" is not stable. The interests demanding of virtual alliance participants are competitive. On the principle of maximizing the profits , price negotiations are inevitable, which lead the virtual union very easy to collapse.

Therefore, the virtual Alliance is extremely unstable, and will eventually lead to "non-cooperative" status.

\subsection{The Allocation Of Cooperation}

If you want the stability of the union, the residual must be allocated.

Characteristic payoff functions are as follows:

Table 5 CHARACTERISTICS PAYOFF OF THE AGRICULTURAL PRODUCTS LOGISTICS COOPERATION

\begin{tabular}{|l|l|l|l|l|l|l|l|}
\hline Union & $\{\mathrm{A}, \mathrm{B}, \mathrm{C}\}$ & $\{\mathrm{A}, \mathrm{B}\}$ & $\{\mathrm{A}, \mathrm{C}\}$ & $\{\mathrm{B}, \mathrm{C}\}$ & $\{\mathrm{A}\}$ & $\{\mathrm{B}\}$ & $\{\mathrm{C}\}$ \\
\hline $\mathrm{V}(\mathrm{S})$ & 430 & 235 & 275 & 286 & 100 & 120 & 150 \\
\hline
\end{tabular}

Note: A, B , C respectively refer to farmers, logistics providers and supermarkets.

Table 6 THE MARGINAL CONTRIBUTION OF PARTICIPANTS

\begin{tabular}{|c|c|c|c|c|c|c|c|}
\hline Union(S) & $\{\mathrm{A}, \mathrm{B}, \mathrm{C}\}$ & $\{\mathrm{A}, \mathrm{B}\}$ & $\{\mathrm{A}, \mathrm{C}\}$ & $\{\mathrm{B}, \mathrm{C}\}$ & $\{\mathrm{A}\}$ & $\{\mathrm{B}\}$ & $\{\mathrm{C}\}$ \\
\hline $\mathrm{V}(\mathrm{S})$ & 430 & 235 & 275 & 286 & 100 & 120 & 150 \\
\hline $\begin{array}{c}p(S-i), \\
i \in\{A, B, C\}\end{array}$ & $\frac{(3-1) !(3-3) !}{3 !}=\frac{1}{3}$ & $\frac{(2-1) !(3-2) !}{2 !}=\frac{1}{6}$ & \multicolumn{2}{|c|}{$\frac{(1-1) !(3-1) !}{3 !}=\frac{1}{3}$} \\
\hline$\Delta_{A}(S)$ & $430-286$ & $\begin{array}{c}235-12 \\
0\end{array}$ & $\begin{array}{c}275-15 \\
0\end{array}$ & & 100 & & \\
\hline$\Delta_{B}(S)$ & $430-275$ & $\begin{array}{c}235-10 \\
0\end{array}$ & $\begin{array}{c}275-10 \\
0\end{array}$ & $286-120$ & & & 120 \\
\hline$\Delta_{C}(S)$ & $430-235$ & $\quad$ & $286-150$ & & 150 \\
\hline
\end{tabular}




$$
\begin{aligned}
\Phi_{A}(V)= & \frac{(3-1) !(3-3) !}{3 !}[V(\{A, B, C\})-V(\{B, C\})] \\
& +\frac{(2-1) !(3-2) !}{3 !}[V(\{A, B\})-V(\{B\})] \\
& +\frac{(2-1) !(3-2) !}{3 !}[V(\{A, C\})-V(\{C\})] \\
& +\frac{(1-1) !(3-1) !}{3 !}[V(\{A\})-V(\{0\})] \\
= & 121.3
\end{aligned}
$$

Table 7 Profits ALlOCATION OF COOPERATIVE GAME

\begin{tabular}{|l|l|l|l|}
\hline & A & B & C \\
\hline$\Phi_{i}(V)$ & 121 & 137 & 172 \\
\hline
\end{tabular}

\section{Conclusions}

There are three basic categories of agents in agricultural products logistics cooperation: farmers, logistics providers, and supermarkets. Establishment of cooperation are important methods of raising revenue. Equitable allocation is the key to ensure the cooperation continuing effectively. There are two methods of allocation, one is based on input, another is based on output. Either allocation method is a relatively fair and reasonable, and is a process for all participants to improve their profits. There is not an absolutely optimal allocation model.

\section{Acknowledgement}

This research was financially supported by the National Natural Science Foundation of China (No. 71540013), Social Science Key Projects of Jiangsu province(13EYA003) and Jiangsu Philosophy and Social Sciences in colleges(2014ZDIXM019).

\section{References}

[1] L.S. Shapley, A value for n-person games, in: Contributions to the Theory of Games, Annals of Mathematics Studies, vol. 2, issue. 28, pp. 307-317,1953.

[2] R.J. Aumann, L.S. Shapley, Values of non-atomic games, A Rand Corporation Research Study, Princeton University Press, Princeton, NJ, 1974.

[3] Roth, Alvin E., ed. The Shapley Value: Essays in Honor of Lloyd S. Shapley. Cambridge: Cambridge University Press, 1988.

[4] Ruiz Garcia, Steinberger G, Rothmund M, A model and prototype implementation for tracking and tracing agricultural batch products along the food chain . Food Control, issue.21, pp. 112-121, 2010.

[5] Martinez-Sala A S, Egea-Lopez E, Garcia-Sanchez F, Tracking of Returnable Packaging and Transport Units with active RFID in the grocery supply chain. Computer in Industry,issue.60, pp. 161-171, 2008. 